\title{
Childhood Mortality: Trends and Determinants in Ethiopia from 1990 to 2015-A Systematic Review
}

\author{
Yohannes Mehretie Adinew, ${ }^{1}$ Senafikish Amsalu Feleke, ${ }^{2}$ \\ Zelalem Birhanu Mengesha, ${ }^{2}$ and Shimelash Bitew Workie ${ }^{1}$ \\ ${ }^{1}$ College of Health Sciences and Medicine, Wolaita Sodo University, Wolaita Sodo, Ethiopia \\ ${ }^{2}$ Department of Reproductive Health, Institute of Public Health, University of Gondar, Gondar, Ethiopia
}

Correspondence should be addressed to Yohannes Mehretie Adinew; yohannes1979@gmail.com

Received 11 February 2017; Revised 13 April 2017; Accepted 28 May 2017; Published 16 July 2017

Academic Editor: Jennifer L. Freeman

Copyright (C) 2017 Yohannes Mehretie Adinew et al. This is an open access article distributed under the Creative Commons Attribution License, which permits unrestricted use, distribution, and reproduction in any medium, provided the original work is properly cited.

\begin{abstract}
Background. Millennium Development Goal 4 calls for reducing under-five mortality rate by two-thirds between 1990 and 2015. The aim of this review was to assess trend of childhood mortality and its determinants from 1990 to 2015 in Ethiopia. Methods. A systematic literature search was conducted in the databases of PubMed and Ovid Medline, Cochrane Library, national medical journals, government websites, and Google Scholar. Original observational study designs and reports conducted entirely or in part in Ethiopia that included a primary outcome variable of childhood mortality and published between 1990 and 2015 were included. Ascertained relevant articles were appraised and the findings were integrated into a systematic review. Results. Childhood mortality has declined in Ethiopia with more pronounced reduction over the last 10 years. Under-five mortality is $72 \%$ lower now than it was 25 years ago, with the pace of decline in infant mortality (83\%) somewhat faster than child mortality (76\%). The corresponding decline in neonatal and postneonatal mortality over the same period was $64 \%$ and $68 \%$, respectively. Parental sociodemographic, socioeconomic, and behavioral variables and nutritional, environmental, and sanitary factors have been identified to affect child survival. Conclusion. Ethiopia has successfully achieved the Millennium Development Goal 4 to reduce under-five mortality.
\end{abstract}

\section{Background}

The Millennium Development Goals (MDGs) were demarcated to be measured over the period from 1990 to 2015 [1]. The objective of MDG 4 was to reduce mortality in children under-five years of age by two-thirds. Attaining the MDGs was expected to be tough for the developing nations [2]. As global drive for improving child survival rises, monitoring global and country level progress has become critical. The limited availability of data poses a significant challenge on generating accurate estimates of under-five mortality (U5M), probability of dying between birth and the fifth birthday, for many developing nations [3].

Large and increasing differences are observed in childhood mortality among world regions. The rate of decline in childhood mortality (CM), the probability of dying between exact ages of one and five, has accelerated over the past fifteen years [4], but high rates remain in sub-Saharan Africa where one child in every eight dies before age of five [5].

Ethiopia is one of the high burden child mortality (CM) countries in Sub-Saharan Africa [6]. Few records available on CM in Ethiopia appear with different rates, underpinning the high CM burden. At the beginning of the MDGs (1990) neonatal mortality (NM), probability of dying within the first month of life, and postneonatal mortality (PNM), probability of dying between the 5th and 52nd week of life, were 63 and 70 while infant mortality (IM), probability of dying between birth and the first birthday, and U5M were 133 and 216 per 1000 live births, respectively $[7,8]$.

In contrast to the then set MDG 4 target of 68 deaths per thousand live births [9], there have been appreciable reductions in CM fifteen years down the road. Ethiopia appreciably performed well to cut child deaths. Despite the significant progress in reducing child deaths, children from poorer or 
rural households remain disproportionately vulnerable $[3,9]$, as child survival interventions are not reaching the children who need them most. Childhood infections, breastfeeding, health service take-up, and maternal sociodemographic characteristics are known to have proximal effect on child survival while hygiene practices, standard of living index, and residence have distal effect $[5,10,11]$. The identification of country specific determinants of CM is a crucial step in planning and implementation of interventions [4]. So the aim of this review was to assess national progress in reducing childhood mortality and identify factors favoring and constraining the overall trend.

\section{Methods and Materials}

This systematic review was conducted and reported according to the PRISMA (Preferred Reporting Items for Systematic Reviews and Meta-Analysis) statement checklist [12].

\subsection{Eligibility Criteria}

2.1.1. Type of Records. This review considers all observational study designs (cross-sectional, cohort, and case control studies) and government reports that assessed neonatal, postneonatal, infant, child, and under-five mortality and determinants of childhood mortality in Ethiopia. The records published between 1990 and 2015 were included. Meeting abstracts and editorial letters were excluded.

2.1.2. Type of Outcomes. This review considers records reported on primary outcome variable of neonatal, postneonatal, infant, child, and under-five mortality and cause and determinants of childhood mortality in Ethiopia.

2.2. Search Strategy. Computer based literature searches were done up to December 30, 2015, by (YM, SA) in the databases of PubMed and Ovid Medline, the Cochrane Library, national medical journals, Google Scholar, and government websites. The literature search was more enhanced by browsing the websites of major publishers (Oxford University Press, Wiley-Blackwell, Elsevier, and Nature Publishing Group) and by searching the references of the obtained records. The website of MEASURE DHS was also visited for the final reports of Demographic and Health Surveys (DHS) of Ethiopia. For local grey literatures that were unavailable electronically, manual search was conducted in university libraries and health bureau. The following search terms were used: "MDGs", "Ethiopia", "NM", "PNM", "IM", "CM", and "U5M" using the Boolean logic (AND, OR) by both authors. The search was peer-reviewed by ZB to increase its comprehensiveness.

2.3. Study Selection and Identification. Retrieved records were categorized as "eligible for full document review" and "ineligible for full document review" based on title and abstract assessment. Records that were grouped as "eligible for full document review" were fully reviewed to decide whether to include them in the review or not. Selection of records was independently done by YM and SA. Differences between records were settled through discussion (based on inclusion and exclusion criteria), reexamining the specific records jointly and consulting $\mathrm{ZB}$ for arbitration.

2.4. Data Extraction. YM and SA extracted the data independently by using same data extraction tool. $\mathrm{ZB}$ and $\mathrm{SB}$ verified the extracted data in order to reduce selection bias and minimize individual errors. Differences among researchers were settled by reevaluating the records until agreement was reached. Extracted information included (i) name of the first author, (ii) year of publication, (iii) objective, (iv) study area, (v) sample population, (vi) neonatal mortality, (vii) postneonatal mortality, (viii) infant mortality, (ix) child mortality, (x) under-five mortality, and (xi) causes and determinants of CM (Table 1). In case of any missing information or uncertainty during records review, efforts were made to contact the authors for clarification.

2.5. Synthesis of the Results. Synthesis was done by constructing a clear descriptive summary of the included records. This was done by tabulating details about name of author, year of study or year of publication, number of participants, and major findings. Results were appraised in a descriptive way according to the facts extracted from each of the comprised records.

\section{Results}

3.1. Description of Records. We aimed to describe Ethiopia's childhood mortality trends and determinants in 1990-2015. Selection of records for this study is depicted in the flow chart (Figure 1). Among 142 records identified by manual search and online browsing, 48 were duplicates and discarded. Out of the remaining 94 records, 78 were excluded based on title/abstract. Sixteen records were selected for a full-text analysis. Of these fully reviewed records, seven were later excluded as they did not fulfill the criteria.

3.2. Trend of Childhood Mortality. Achieving the MDG 4 was always likely to be very difficult for low-income countries [2]. In 1990 U5MR in Ethiopia was about 216 per 1000 live births, and child survival MDG for Ethiopia was 68 deaths per 1000 live births [1].

In 1990-1995, neonatal mortality and PNM were 63 and 70, while infant mortality and CM were 133 and 96 per 1000 live births, respectively. U5M during the same period was 216 per 1000 live births $[1,7,13,14]$. For the period 1996-2000, the age distribution of U5M was $29 \%$ NM, 29\% PNM, and $42 \%$ CM. Ethiopia was among the top five nations in NM. In Ethiopia, NM accounts for a smaller (29\%) share of U5M than the average for the developing world $(36 \%)[9,10]$.

In 2000 Ethiopian Demographic and Health Survey (EDHS), the IMR and U5M in the five years preceding the survey were 95 and 165 deaths per 1,000 live births. This means that one in every ten Ethiopian children dies before reaching age one, while one in every six does not survive to their fifth birthday [10].

The 2005 EDHS reported that IM has declined by $19 \%$ over the five-year period preceding the survey from 97 to 77 , 
TABLE 1: Characteristics of studies that met the inclusion criteria and were included in the systematic review.

\begin{tabular}{|c|c|c|c|c|}
\hline Author & Study area & Objective & $\begin{array}{l}\text { Population } \\
\text { sampling }\end{array}$ & Findings \\
\hline $\begin{array}{l}\text { You et al., } \\
2015[1]\end{array}$ & $\begin{array}{l}\text { Global, regional, } \\
\text { and national }\end{array}$ & $\begin{array}{l}\text { To assess levels and trends in } \\
\text { under-5 mortality between } \\
1990 \text { and } 2015\end{array}$ & & $\begin{array}{l}\text { The U5MR in Ethiopia in } 1990 \text { was } 205 \text {, in } 2000 \text { was } \\
\text { 145, and in } 2015 \text { was 59, which is lower than the target } \\
68 \text {. The annual rate of reduction was } 5\end{array}$ \\
\hline EDHS, 2005 [5] & Country-wide & $\begin{array}{l}\text { To assess the demographic } \\
\text { and health condition in the } \\
\text { country }\end{array}$ & $14,500 \mathrm{HH}$ & $\begin{array}{c}\text { NMR (39), PNMR (38), IMR (77), CMR (50), and } \\
\text { U5MR (123) }\end{array}$ \\
\hline $\begin{array}{l}\text { Wang et al., } \\
2014[7]\end{array}$ & $\begin{array}{l}\text { Global, regional, } \\
\text { and national }\end{array}$ & $\begin{array}{l}\text { To assess levels of neonatal, } \\
\text { infant, and under-5 mortality } \\
\text { during 1990-2013 }\end{array}$ & & $\begin{array}{l}\text { NMR (22.9), PNMR (23.3), CMR (23.2), and U5MR } \\
\text { (74) }\end{array}$ \\
\hline $\begin{array}{l}\text { Ministry of } \\
\text { Health, Family } \\
\text { Health } \\
\text { Department, } \\
2005 \text { [9] }\end{array}$ & Country-wide & $\begin{array}{l}\text { National Strategy for Child } \\
\text { Survival in Ethiopia }\end{array}$ & Document & $\begin{array}{c}\text { Children in Ethiopia suffer from poor health. The } \\
\text { national U5MR is about } 140 / 1000 \text {, with variations } \\
\text { among the regions from } 114 \text { to } 233 / 1000 \text {. The levels of } \\
\text { mortality are worsened particularly by poverty, } \\
\text { inadequate maternal education, lack of potable water } \\
\text { and sanitation, high fertility, and inadequate birth } \\
\text { spacing }\end{array}$ \\
\hline $\begin{array}{l}\text { National } \\
\text { Planning } \\
\text { Commission } \\
\text { and the United } \\
\text { Nations in } \\
\text { Ethiopia, } 2014 \\
\text { [11] }\end{array}$ & Country-wide & $\begin{array}{l}\text { To assess Ethiopia's progress } \\
\text { towards the MDGs }\end{array}$ & Report & $\begin{array}{l}\text { U5M declined to } 60 \text { per } 1,000 \text { live births in } 2015 \text {, which } \\
\text { is below the MDG target of } 63 \text { indicating that Ethiopia } \\
\text { has achieved its target of reducing child mortality by } \\
\text { two-thirds ahead of time. Similarly, the infant mortality } \\
\text { rate declined from } 123 \text { (per } 1000 \text { live births) in } 1990 \text { to } \\
97 \text { in } 2000,77 \text { in } 2005 \text {, and } 59 \text { in } 2011 \text {, but it is unlikely } \\
\text { that the MDG target of } 31 \text { per } 1,000 \text { live births in } 2015 \\
\text { will be attained. Neonatal deaths (per 1,000 live births) } \\
\text { showed a decline over time from } 54 \text { in } 1990 \text { and } 49 \text { in } \\
2000 \text {, to } 37 \text { in } 2011\end{array}$ \\
\hline $\begin{array}{l}\text { Oestergaard et } \\
\text { al., } 2011[14]\end{array}$ & $\begin{array}{l}\text { Global, regional, } \\
\text { and national }\end{array}$ & $\begin{array}{l}\text { To assess neonatal mortality } \\
\text { levels for } 193 \text { countries in } 2009 \\
\text { with trends since } 1990\end{array}$ & $\begin{array}{l}\text { Compiled a } \\
\text { database of } \\
\text { NMR and } \\
\text { U5MR }\end{array}$ & NMR in 2009 was between 30 and 45 \\
\hline EDHS, 2000 [13] & Country-wide & $\begin{array}{l}\text { To assess the demographic } \\
\text { and health condition in the } \\
\text { country }\end{array}$ & $\begin{array}{c}1,355 \\
\text { couples } \mathrm{HH}\end{array}$ & $\begin{array}{c}\text { NMR (49), PNMR (48), IMR (97), CMR (77), and } \\
\text { U5MR (165) }\end{array}$ \\
\hline EDHS, 2011 [14] & Country-wide & $\begin{array}{l}\text { To assess the demographic } \\
\text { and health condition in the } \\
\text { country }\end{array}$ & $\begin{array}{l}\text { More than } \\
17,000 \\
\text { households }\end{array}$ & $\begin{array}{c}\text { NMR (37), PNMR (22), IMR (59), CMR (31), and } \\
\text { U5MR (88) }\end{array}$ \\
\hline $\begin{array}{l}\text { World Bank, } \\
2014 \text { [15] }\end{array}$ & $\begin{array}{l}\text { Global, regional, } \\
\text { and national }\end{array}$ & & & U5MR was 64.40 in 2013 \\
\hline
\end{tabular}

NMR: neonatal mortality rate; PNMR: postneonatal mortality rate; IMR: infant mortality rate; CMR: child mortality rate; U5MR: under-five mortality rate; HH: household.

while U5M has gone down by $25 \%$ from 165 to 123 deaths per 1,000 live births. The corresponding decreases in neonatal mortality and PNM over the same period were $15 \%$ and $22 \%$, respectively [5]. Infant mortality and U5MR attained for the five years preceding the two surveys confirmed declining trend in mortality $[5,9,10,13]$.

In 2011 EDHS, the IM and CM were 59 and 31 deaths per 1,000 live births, while the overall U5MR for the same period was 88 . Neonatal mortality and PNM were 37 and 22 deaths per 1,000 live births, respectively. The survey showed a rapid decrease in infant mortality and U5M during the 5 years prior to the survey compared to the 2005 EDHS. For example, IM has decreased by $23 \%$, from 77 to 59 , while U5M has decreased by $28 \%$, from 123 to 88 deaths per 1,000 live births [11].
In 2015 NM and PNM are 23 and 22 per 1,000 live births, respectively. U5M was also 59 per 1,000 live births, with one in every sixteen children dying before their fifth birthday $[5,15]$. Generally, the trend analysis showed that Ethiopia has achieved MDG 4; U5M fell by 72\% compared with 1990 figures, which is $2.88 \%$ annual decrease. IM reduced from 133 to 23 accounting for $83 \%$ reduction. The annual decrement for IM was $3.32 \%$. CM reduced from 96 to 23 deaths per 1000 live births which is $76 \%$ reduction; this means CM was dropping by nearly $3 \%$ annually. Neonatal mortality and PNM dropped from 63 to 23 and 70 to 22, respectively, with respective annual fall of 2.2 and $2.7 \%$ (Figures 2 and 3 ).

3.3. Determinants of Childhood Mortality. Parental sociodemographic, socioeconomic, and behavioral variables and 


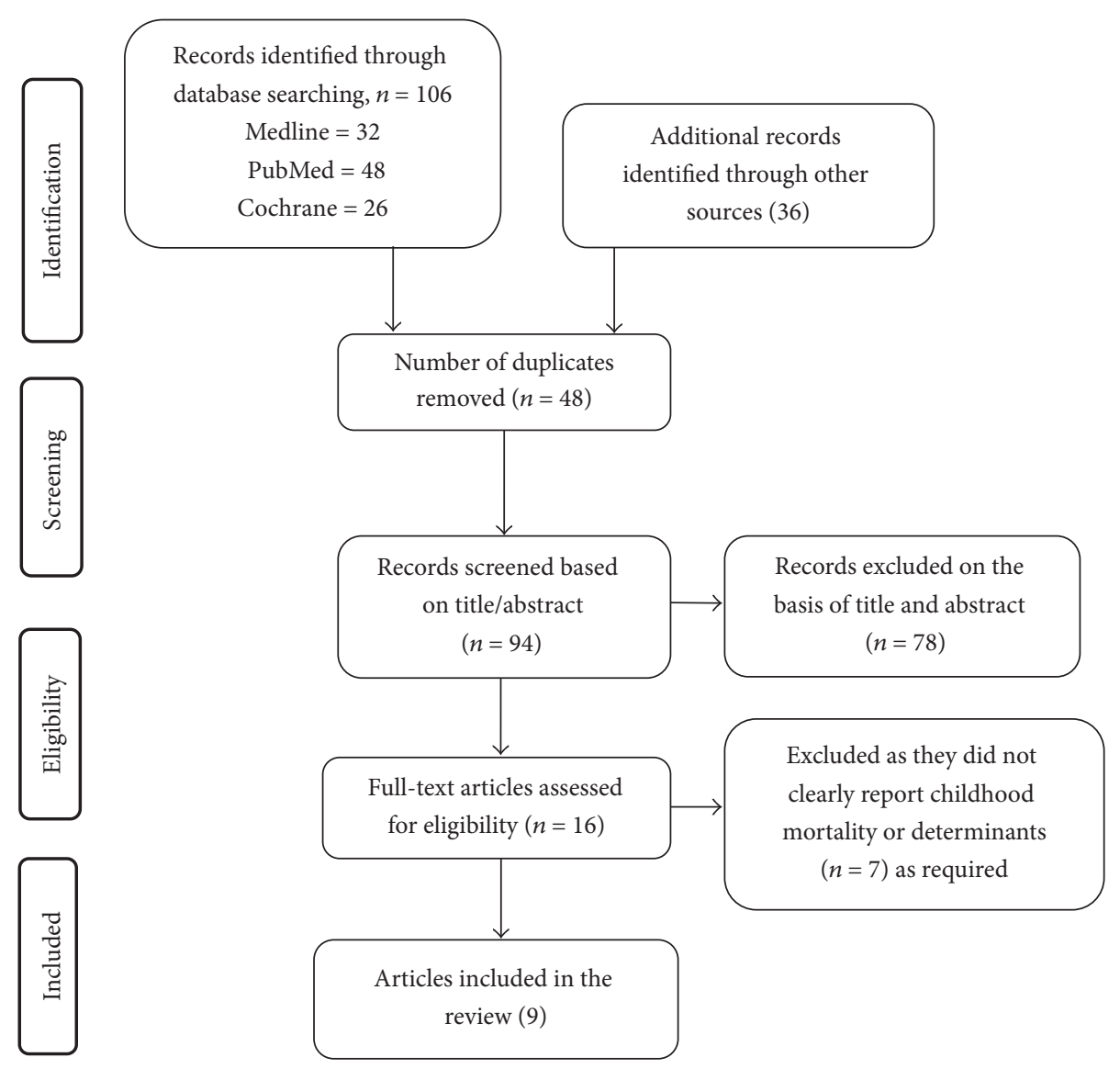

FIGURE 1: Flow diagram showing the procedure of selecting records for systematic review.

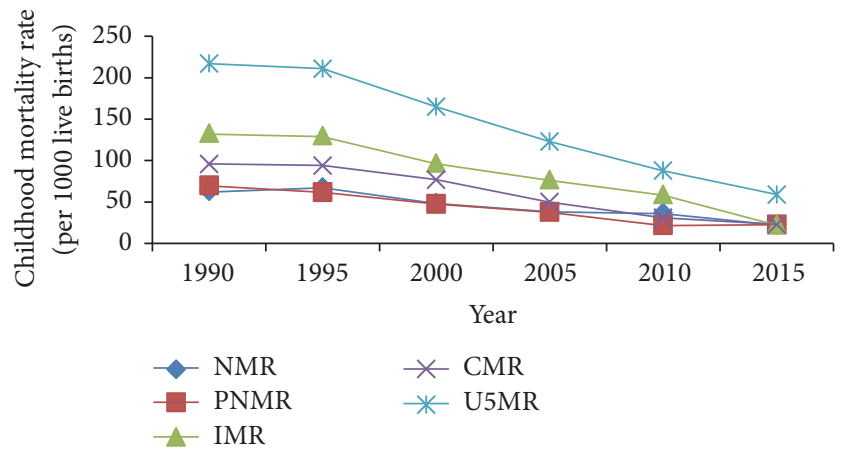

Figure 2: Overall trend on under-five mortality from 1990 to 2015 in Ethiopia $[1,5,7,9-13,15]$.

nutritional, environmental, and sanitary factors have been identified to affect child survival. Among identified determinants, maternal education, maternal age at first birth and mothers' marital status, preceding birth interval, birth order, breastfeeding, infections, healthcare, family income, and hygiene practice were found to be important determinants of childhood mortality.

3.4. Maternal Education. The review revealed important role maternal education played in the reduction of child

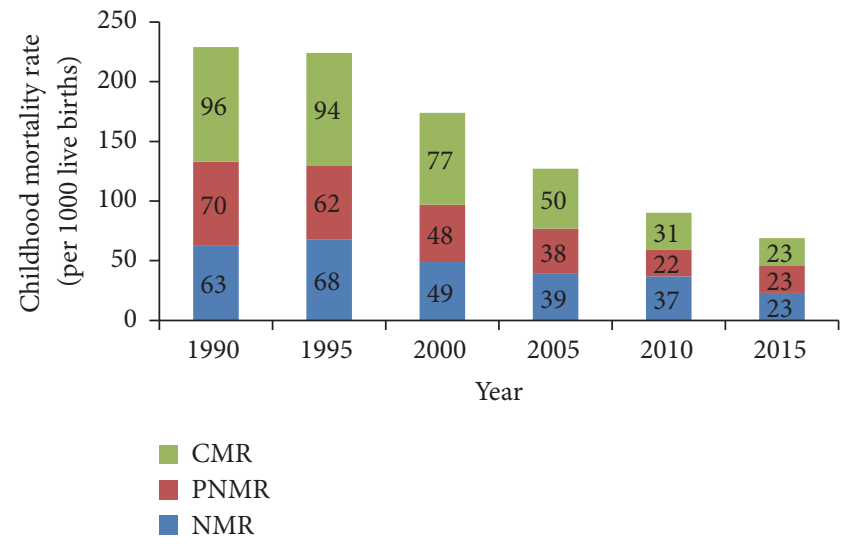

FIgure 3: Progressive contribution of NM, PNM, and CM to U5MR from 1990 to 2015 in Ethiopia [1, 5, 7, 9-13, 15].

mortality. One of the pathways by which mothers' education affects child survival is through improved child care [17]. Records revealed that neonatal mortality [18] and U5M [19] were associated with parental illiteracy; particularly maternal education has a strong relation with CM [20]. Children born to mothers with secondary education had a significantly reduced IM [16, 21]. Similarly in Jimma epidemiological assessment of determinants and causes of CM in 2004, 


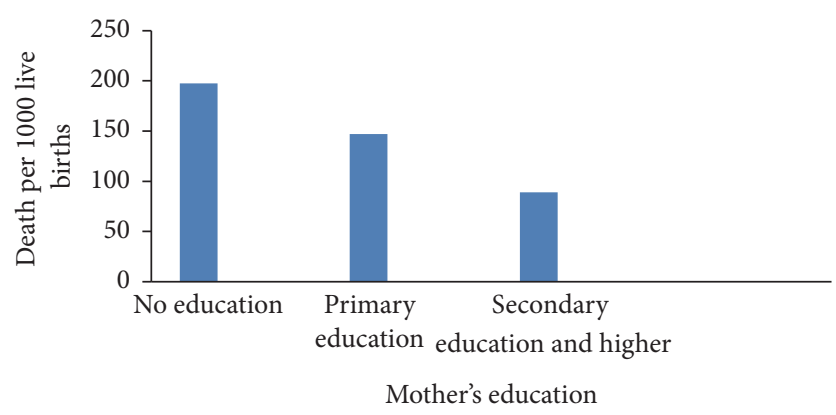

FIGURE 4: Under-five mortality by mothers' educational status in Ethiopia, 2011 [11].

a reduction in death was observed in children of mothers with secondary or above level of education [22]. In Gilgel Gibe field research of determinants of U5M, children born to mothers whose educational level was below elementary were 14 times more likely to die compared to children whose mothers' education is above elementary [23].

Further analysis of the 2011 EDHS reveals that risk of dying for a child born to uneducated mother was 2.13 times higher compared to a child whose mother had primary and higher education [24]. In another study that analyzed birth history information of live births from the 2000, 2005, and 2011 EDHS to assess trends and determinants of NM in Ethiopia, neonates born to women with secondary or higher schooling had a lower risk of dying compared to neonates born to women with no education [25] (Figure 4).

3.5. Preceding Birth Interval. Birth interval with previous child has a strong relationship with CM [20]. Analysis of the 1997 community and family survey data in Southern Ethiopia revealed that the risk of IM is significantly associated with short birth intervals of less than 18 months compared with an interval of 24-35 months [16]. In other records mortality among neonates $[18,25,26]$ and infants [27] with a preceding birth interval of less than 24 months was found to be 2 times higher than those with a preceding birth interval of greater than 24 months. In epidemiological assessment of determinants of U5M in Jimma town, highest rate of death was observed in groups with short birth interval [22].

Data from EDHSs of 2000 and 2005 revealed higher IM among those with birth interval below two years [28]. In general, children born after long birth intervals (lasting three years or more) appear to have better survival chances in all these age periods [16]. This means that as the previous birth interval increased the risk of infant and child mortality decreased [29]. Age-specific mortality patterns indicate that the adverse effects of short interval are strongest in the infant period but appear to weaken in the 1-4 age categories [30]. Children from multiple births (twins, triplets, etc.) also experience much higher mortality than single births [28] (Figure 5).

3.6. Mother's Age at First Birth. This review revealed that mother's age at first birth is negatively correlated with IM. Its effect (except children born to mothers older than 20

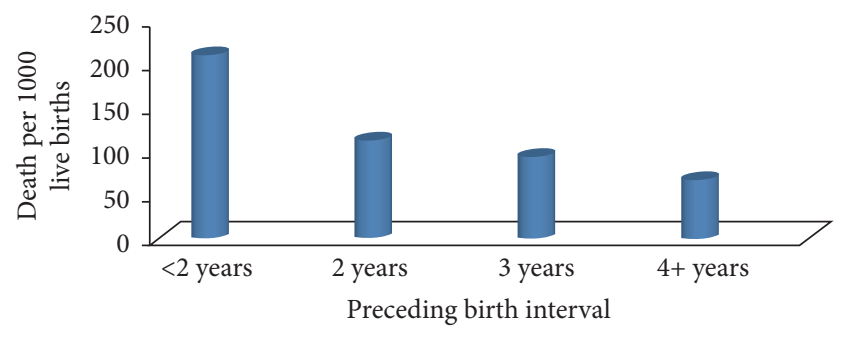

FIGURE 5: Under-five mortality by preceding birth interval in Ethiopia, 2000 [16].

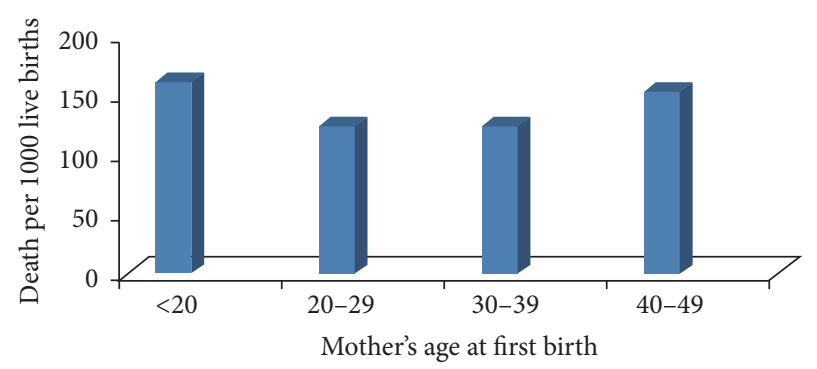

FIGURE 6: Under-five mortality by mother's age at first birth in Ethiopia, 2005 [5].

years of age at first births) has a significant impact on CM [29]. In particular, neonatal mortality and IM are very much influenced by the age of the mother [22]. Births to mothers in the age group of 15-19 face higher mortality risk than births to mothers in the age group of 25-29 or 30-34 [16]. The risk of IM has decreased as mother's age at first birth increased [29]; that is, the risk of IM has been high for mothers who had their first child at younger age $[24,26,29]$. Further analysis from the EDHS revealed that neonates born to mothers aged less than 18 years have higher mortality [25]. The risk of mortality is higher for children born from teenage mother and mothers aged 40-49 years (90 per 1000) [30] (Figure 6).

3.7. Marital Status of the Mother. Single mothers had increased infant mortality compared to the married ones [22]. In both previous five-year periods of 2000 and 2005, children born to married women play a significant role in the reduction of IM in comparison to children born to other categories [29]. In study of determinants of mortality among one- to four-year-old children in Ethiopia,a child born to currently unmarried mothers had a $51.3 \%$ higher risk of dying than children born to currently married mothers [24].

3.8. Breastfeeding. The role breastfeeding plays in prolonging birth intervals and reducing fertility which in turn reduces CM is critical [16]. Further analysis in both 2000 and 2005 EDHS confirmed that breastfeeding is the most important factor for reducing IM and death rate was lower for neonates who were put to breast immediately upon birth [29]. Children never breastfed had higher risk of dying than those who were breastfed [31]. The likelihood of death among children who were not breastfed was 6 times higher compared to their counterparts [23]. Infants not exclusively breastfed and given 


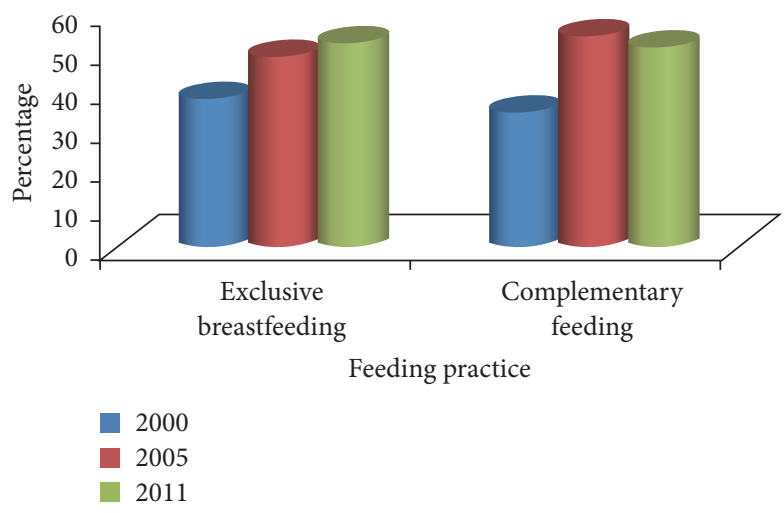

Figure 7: Trends in exclusive and complementary feeding in Ethiopia from 2000 to $2011[5,10,11]$.

breast milk after 24 hours of birth had higher mortality than their counterparts with IRR $=7.86,95 \% \mathrm{CI}:(5.11,12.10)$ and IRR $=4.84,95 \% \mathrm{CI}:(2.94,7.99)$, respectively [32]. A community based study done using verbal autopsy method in Gondar revealed that malnutrition is one of the causes of childhood mortality [33]. Childhood wasting, underweight, and stunting were also the main risk factors for under-5 mortality, but all improved dramatically during the MDG era [34] (Figure 7).

3.9. Infections. Acute childhood diarrhea is the leading cause of death in children under five in Ethiopia, which is largely the result of lack of access to safe water, poor environmental condition, and crowded living conditions [35]. In Gilgel Gibe field research center 2005, the most common causes of neonatal deaths were prematurity $(26.4 \%)$, pneumonia (22.6\%), neonatal tetanus (9.4\%), and sepsis (7.5\%). The main reasons of postneonatal and child mortalities were malaria, diarrheal diseases, meningitis, and pneumonia. Diarrheal diseases were the primary cause of death for children above one year. Measles was an important contributing factor for $7 \%$ of PNM. Injury and HIV/AIDS were accountable for $5 \%$ of U5M [23]. Figures from the three EDHSs also confirm that malaria, diarrhea, and pneumonia are the common causes of under-five mortality $[5,10,11]$ (Figure 8).

3.10. Health Service Utilization. One of the reasons behind the observed success in reducing under-five mortality has been the expansion of the coverage of health service. The health infrastructure and health extension programs have expanded significantly. As a result the ratio of health facilities to the population showed great improvements. For example, the ratio for health posts reached 1:5,352 while the ratio of health centers declined from $1: 37,299$ in $2009 / 10$ to $1: 27,706$ in $2012 / 13$. Primary health service coverage reached $93.4 \%$ of the population in $2012 / 13$ and $94.0 \%$ in $2013 / 14$ [13].

Another important element in the reduction of child mortality is immunization. Immunization for measles and DPT3 are important contributors to reducing child mortality. In 2013/14, pentavalent 3 immunization coverage was $91.1 \%$, pneumococcal conjugate vaccine (PCV) immunization coverage was $85.7 \%$, measles immunization coverage was $86.5 \%$,

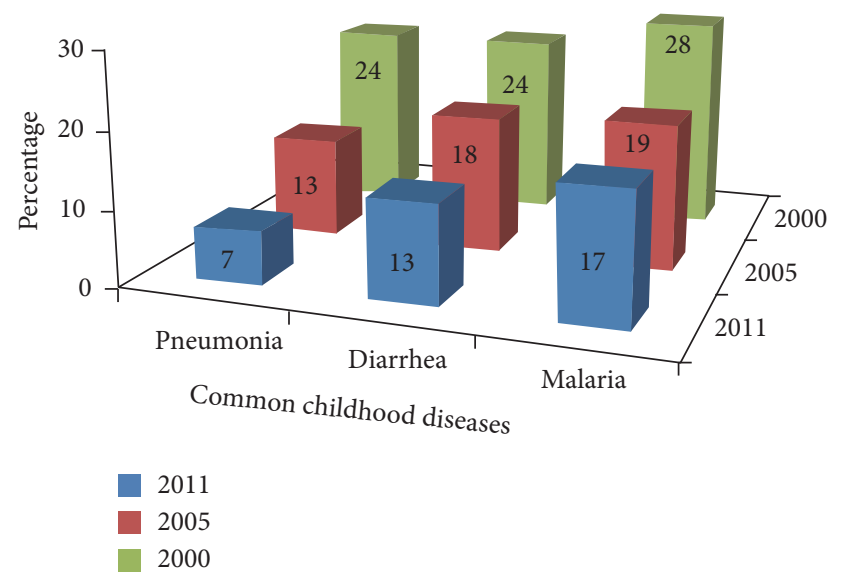

Figure 8: Trends of the common causes of under-five mortality in Ethiopia from 2000 to 2010 [5, 10, 11].

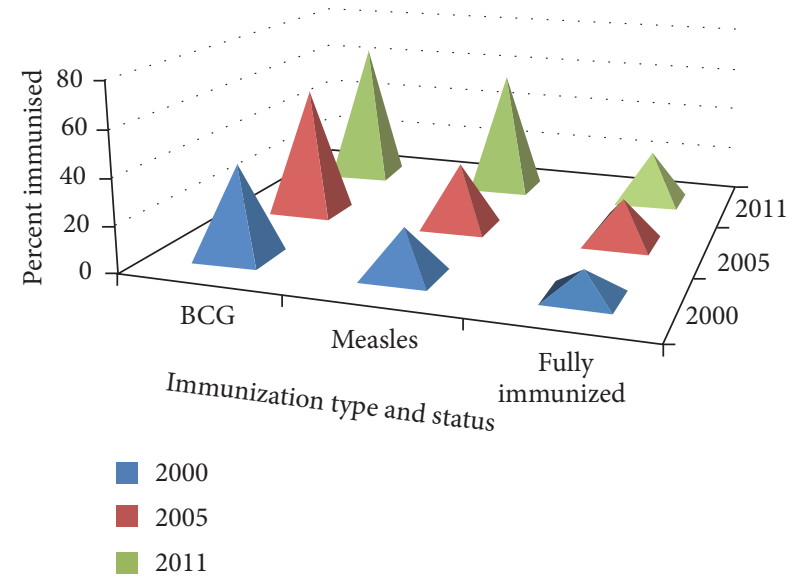

FIgURE 9: Trends of child immunization in Ethiopia from 2000 to $2011[5,10,11]$.

and the percentage of fully immunized children was $82.9 \%$ [13].

A community based case control study conducted in Jimma revealed excess mortality among children who had never been immunized [31]. Unvaccinated children had highest U5M compared to those who were vaccinated at least once [36]. Neonates whose mothers attended antenatal visits exhibited lower risk of death than those whose mothers did not [26]. Mothers who did not attend antenatal care during their pregnancy had greater risk of experiencing infant death compared to those mothers who did at least once. In addition giving two tetanus toxoid injections to the mothers before childbirth decreased NM [25]. The EDHSs revealed improvement in utilization of child and maternal healthcare services $[5,10,11]$ (Figures 9 and 10). High risk of $\mathrm{U} 5 \mathrm{M}$ was observed when the mothers had no good practice of infection prevention and negative perception on severity of illnesses and modern treatment [23].

3.11. Birth Order. An increase in children birth orders showed a tremendous negative impact on IM in both 2000 and 


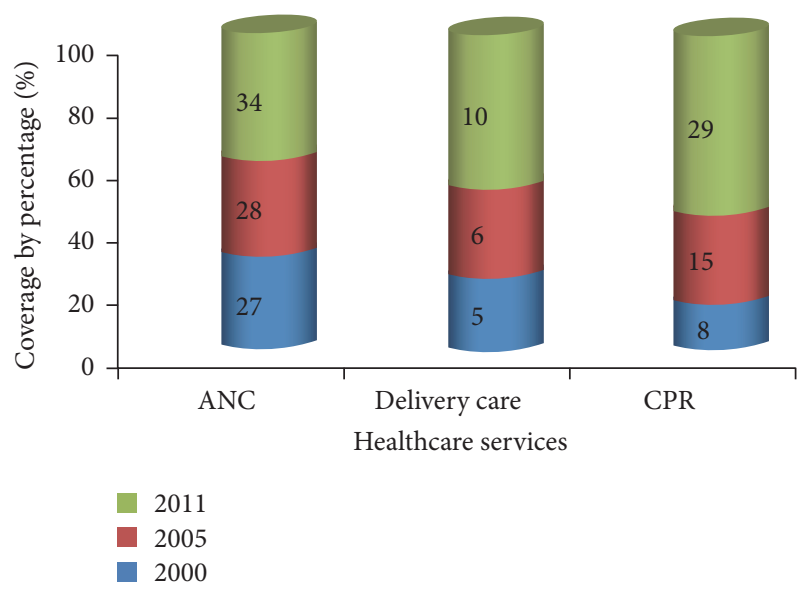

Figure 10: Trends in the use of healthcare facility services in Ethiopia from 2000 to 2011 [5, 10, 11].

2005 EDHSs; particularly the 2nd and 3rd birth order were dominant determinants $[5,7,10]$. The estimated hazard ratios of mortality were higher for first birth order compared to second and third ones [26]. In 2005 EDHS, IM among children born in 4th-7th birth order was low compared to those born in 2nd-3rd birth order. Therefore the U-shape relationship between birth order and IM confirmed that the risk of IM is higher for the first and for more than 7th birth order. A study based on the 2011 EDHS data reported that a first born child had a 2 times higher risk of dying than a child belonging to orders four and more [24]. As expected, multiple births were positively associated with CM in both 2000 and 2005 surveys [30].

3.12. Standard of Living Index. Standard of living index [SLI] is another important differential factor of CM [37]. Records showed that children in poor families have relatively higher risks of IM compared to those belonging to medium or rich families [16, 21], while higher level of wealth score has shown a significant reduction in CM $[22,36]$. So, it is clear that the mother's SLI plays significant role in CM [37]. A prospective cohort study on trends and risk factors for NM in Butajira revealed that neonates born to poor mothers who had no oxen and lived in thatched houses conferred the highest risk of neonatal deaths [38]. In study done in Jimma from 2004 to 2005, higher level of wealth index was associated with a significant reduction in CM. Excess in mortality was observed in children who reside in household with a floor made of earth compared to that in a household with a floor made of cement [31].

Parental factors affected infants relatively more than the children, especially with regard to Acute Respiratory Infection (ARI) mortality. This was also noted with "absence of window," a proxy measure for evaluating the type of housing [29]. Birth cohort study in South West Ethiopia from 1992 to 1994 identified environmental factors like ventilation in the house and the type of roof and floor and sanitary factors like habit of soap use for hand washing and latrine facility to have association with IM [39].
3.13. Hygiene Practice. Maternal hygienic practice was found to have an association with child survival. Mothers who did not use soap for hand washing had higher infant death than those who used soap [39]. Infants whose mothers were not washing their hands with soap after visiting toilet and before feeding child had high mortality rate than their counterparts [IRR $=4.61,95 \% \mathrm{CI}:(2.24,9.48)]$ [32]. In terms of etiological fractions, a greater number of U5M could be ascribed to parental compared to environmental conditions, with relatively more infants being affected than children [19].

3.14. Residence. According to EDHs childhood mortality in urban areas is consistently lower than in rural areas $[5,10$, 11]. From EDHS 2011, infant mortality is 29 percent higher in rural areas ( 76 deaths per 1,000 live births) than in urban areas (59 deaths per 1,000 live births). Under-five mortality also had difference in urban and rural residence which was 83 deaths and 114 deaths per 1,000 live births [11]. Child mortality was also 34 percent lower in urban areas than in rural areas [10].

\section{Discussion}

The review showed a decreasing trend in childhood mortality. The identified determinants were parental sociodemographic, socioeconomic, and behavioral variables and nutritional, environmental, and sanitary factors.

Ethiopia, a low-income country in the sub-Saharan Africa, has achieved the MDG to reduce the mortality rate for children under the age of five. Sustained government drive brings down deaths among children by $72 \%$ compared with 1990 figures. U5M decreased appreciably well compared to NM. IM fell from 133 to 23 per 1000 live births, $83 \%$ reduction, and CM reduced from 96 to 23 deaths per 1000 live births which is $76 \%$ reduction. Neonatal mortality and PNM have dropped from 63 to 23 and 70 to 22 per 1000 live births, respectively. This means the risk of dying for any Ethiopian child is the same in the first month of life and in the remaining eleven months of the first year of life. Thus, $50 \%$ of infant deaths in Ethiopia occur during the first month of life; and almost one in every twenty babies born in Ethiopia (46.1 per 1,000) does not survive to celebrate their first birthday. Postneonatal and late neonatal deaths are amenable to public health interventions like immunization, breastfeeding, and improved hygiene. The achievement of major reductions in early neonatal deaths will depend on provision of individualized clinical care and quality of services which is much more challenging.

The 2013 progress report of the World Health Organization (WHO), World Bank Group, and UNICEF revealed Ethiopia's success of reducing under-five mortality by more than two-thirds over the past two decades. In 1990 Ethiopia had the seventh highest child death in the world, losing about 216 children in every 1,000 live births. By the year 2012 this rate had decreased to 68, an enormous $67 \%$ drop [6], which was further dropped to $64.4 \%$ in 2013 [15]. Under-five mortality was measured to be 59 deaths per 1000 live births at the end of the MDGs $[1,13]$. This means preventable and treatable conditions are still killing more Ethiopian children in later childhood $[9,10]$. 
Government commitment was central to the achievement. Implementation of the health extension program which deployed over 36,000 health workers to more than 15,000 health posts across the nation is believed to have a lion share in reduction of child deaths. The health extension workers, females who have completed tenth grade and trained in health extension program modules for one year, provide family planning and immunization services; they promote preparedness for birth and readiness for complications and active management of the third stage of labor among others [40]. To achieve these, they work on increasing knowledge and skills of communities and households and creating model families as role model. Since its establishment the HEP has created greater awareness of how to prevent communicable diseases. It also brought change in attitude and behavioral practices in preventive aspects of maternal and child health [41]. But further success in reducing under-five mortality will be very challenging to achieve.

Determinants during the late 20th century include sociodemographic, nutritional, healthcare, sanitary, and environmental factors. In addition within 21 st century wealth index, utilization of family planning service, behavioral factors like child care practice, and negative perception on severity of illness were identified as determinants of U5M.

Education plays a great role in increasing awareness of healthcare. Mainly women's education results in more effective preventive and healthcare practices, which increases their productivity and affects infant mortality and CM [17].

Preceding birth interval was identified as a significant determinant of NM in both 2000 [10] and 2005 [5] EDHSs. The estimated result showed that the impact of preceding birth interval on CM is larger relative to the impact on IM. Short birth interval increases the risk of infant mortality and CM due to physiological and nutrition depletion of the mothers which relate to premature child birth and expose the mother to pregnancy complications [37]. As a result poor nutritional status is more common among children with short birth intervals. Thus the relative risk of being underweight is significantly higher for children of shorter birth intervals. The general trend also showed that children with long birth interval are less likely to face the problem of stunting and underweight $[16,28]$. The proper spacing of births allows more time for childcare to make more maternal resources available for the care of the child and mother [28]. In addition households with maternal mortality had an increased risk of stillbirths and neonatal deaths [18].

Results by comparing 2005 [5] and 2000 [10] EDHS found that breastfeeding is the most important factor for reducing IM. Children breastfed for more than six months highly reduced the risk of IM. This is in line with the majority of Ethiopian mothers' economical statuses, being very poor and having no access to provide alternative nutrition choice for children, and therefore prolonged breastfeeding is common in Ethiopia.

In both periods of 2000 [10] and 2005 [5], children born to married women play a significant role in the reduction of IM in comparison to children born to other categories. This might be due to socioeconomic factors, traditions, and the lifestyle of the unmarried women.
As mother's age at first birth increased, the risk of IM was reduced and mothers who gave birth to their first child at younger age faced high IM risk due to social and reproduction immaturity. However, child gender and mother's age at first birth were significant only for the previous five-year period of 2005 [5] but not 2000 [10].

According to findings from the Global Burden of Disease Study in 2013, Child deaths due to diarrheal diseases that were attributable to unsafe water supply and sanitation declined by more than $60 \%$ between 1990 and 2013 [34]. The source of drinking water is another determinant that was consistently associated with child survival. The result revealed that children born in households with access to nonimproved source of drinking water (river or pond water) were (HR: 2.57, 2.01, and 2.14) more likely to experience the hazard of U5M compared with their counterpart [42].

\section{Conclusion}

Ethiopia has achieved the MDG goal set for child survival. U5M has dropped from 216 to 59 , with $5 \%$ annual rate of reduction. The health extension program and the expansion of health facilities have played a significant part. Age, marital and educational status of mother, birth order, preceding birth interval, and family income were the dominant and the most significant determinants of childhood mortality. Other factors include nutritional factors like breastfeeding and healthcare factors like immunization, antenatal care, and delivery care. On the aspects of the environmental and sanitary factors, adequate ventilation, type of floor and roof of the house, availability of latrine facility, and habit of soap using for hand washing are associated with mortality. Regarding diseases, according to EDHS and WHO reports, the leading causes of this age group death are malaria, diarrhea, and pneumonia. Hence, it is worthwhile to address the appalling inequalities in the distribution and access to health services with a focus on service quality and improved sanitation to effectively mitigate childhood death and disease burden.

\author{
Abbreviations \\ ANC: Antenatal care \\ CM: Child mortality \\ CPR: Contraceptive prevalence rate \\ EDHS: Ethiopian Demographic and Health Survey \\ IM: Infant mortality \\ MDG: Millennium Development Goal \\ NM: Neonatal mortality \\ PNM: Postneonatal mortality \\ U5M: Under-five mortality \\ WHO: World Health Organization.
}

\section{Disclosure}

The current address of Zelalem Birhanu Mengesha is as follows: Translational Health Research Institute (THRI), School of Medicine, Western Sydney University, Penrith, NSW 2751, Australia. 


\section{Conflicts of Interest}

The authors declare no potential conflicts of interest with respect to the research, authorship, and/or publication of this article.

\section{Authors' Contributions}

Yohannes Mehretie Adinew conceptualized the proposal, identified and reviewed all papers, and prepared the manuscript. Senafikish Amsalu Feleke participated in identification and review of the papers. Zelalem Birhanu Mengesha was reviewer and revised subsequent drafts of the paper. Shimelash Bitew Workie reviewed drafts of the paper and edited the manuscript. All authors reviewed the manuscript critically for content and approved the final version to be submitted.

\section{References}

[1] D. You, L. Hug, S. Ejdemyr et al., "Global, regional, and national levels and trends in under-5 mortality between 1990 and 2015, with scenario-based projections to 2030: a systematic analysis by the un Inter-agency group for child mortality estimation," The Lancet, vol. 386, pp. 2275-2286, 2015.

[2] UNICEF and WHO, "Fulfilling the Health Agenda for Women and Children: the 2014 Report," http://www.countdown2015mnch .org/documents/2014Report/The2014report/Countdown_The 2014_Report_final.pdf.

[3] Y. Danzhen, J. Gareth, and T. Wardlaw, "Levels \& Trends in Child Mortality," UN Inter-Agency Group for Child Mortality Estimation, 2010.

[4] R. E. Black, S. S. Morris, and J. Bryce, "Where and why are 10 million children dying every year?" The Lancet, vol. 361, no. 9376, pp. 2226-2234, 2003.

[5] Central Statistical Authority [Ethiopia] and ORC Macro. Ethiopia Demographic and Health Survey,.

[6] World Data Bank, World Development Indicators, The World Bank Group, 2013, http://www.worldbank.org/en/country/ethiopia.

[7] Wang et al., "Global, regional, and national levels of neonatal, infant, and under-5 mortality during 1990-2013: a systematic analysis for the Global Burden of Disease Study 2013," Lancet, vol. 384, no. 9947, pp. 957-979, 2014.

[8] UNICEF, "Child mortality estimates," in Estimates generated by the UN Inter-agency Group for Child Mortality Estimation (IGME), 2014, http://data.unicef.org.

[9] Ministry of Health: Family Health Department, "National Strategy for Child Survival in Ethiopia. Ministry of Health, Addis Ababa," https:/extranet.who.int/nutrition/gina/sites/default/files/ETH\% 202005\%20National\%20Strategy\%20for\%20Child\%20Survival .pdf.

[10] Central Statistical Authority [Ethiopia] and ORC Macro, Ethiopia Demographic and Health Survey, 2000.

[11] Central Statistical Authority [Ethiopia] and ORC Macro, "Ethiopia Demographic and Health Survey," 2011.

[12] D. Moher, A. Liberati, J. Tetzlaff, and D. G. Altman, "Preferred reporting items for systematic reviews and meta-analyses: the PRISMA statement," PLoS Medicine, vol. 6, no. 7, Article ID e1000097, 2009.
[13] National Planning Commission and the United Nations in Ethiopia, "Millennium development goals report: Assessment of Ethiopia's progress towards the MDGs, Addis Ababa," 2014.

[14] M. Z. Oestergaard, M. Inoue, S. Yoshida et al., "Neonatal mortality levels for 193 countries in 2009 with trends since 1990: a systematic analysis of progress, projections, and priorities," PLoS Medicine, vol. 8, no. 8, Article ID e1001080, 2011.

[15] Trading economics, "Mortality rate - under-5 (per 1, 000) in Ethiopia," https://www.tradingeconomics.com/ethiopia/mortalityrate-under-5-per-1-000-wb-data.html, 2014.

[16] M. Ezra and E. Gurum, "Breastfeeding, birth intervals and child survival: Analysis of the 1997 community and family survey data in southern Ethiopia," Ethiopian Journal of Health Development, vol. 16, no. 1, pp. 41-51, 2002.

[17] D. Monica, "Death clustering, mothers' education and the determinants of child mortality in rural Punjab, India," Population Studies, vol. 44, no. 3, pp. 489-505, 1990.

[18] Y. Yaya, K. T. Eide, O. F. Norheim, and B. Lindtjørn, "Maternal and neonatal mortality in south-west ethiopia: estimates and socio-economic inequality," PLoS ONE, vol. 9, no. 4, Article ID e96294, 2014.

[19] D. Shamebo, A. Sandstrom, L. Muhe, L. Freij, I. Krantz, and S. Wall, The Butajira Rural Health Project in Ethiopia: A Nested Case Referent (Control) Study of Under-5 Mortality And Its Public Health Determinants, vol. 71, WHO, 1993.

[20] Dr. P. Prashanth Kumar and Gemechis, "Infant and child mortality in Ethiopia: a statistical analysis approach," Ethiopian Journal of Education and Sciences, vol. 5, no. 2, 2010.

[21] UNDP., "Sustainable development goals," http://www.et.undp .org/content/ethiopia/en/home/mdgoverview/overview/mdg4 .html, 2015.

[22] G. Belaineh, Epidemiological Assessment of Determinants and Causes of under-five Child Mortality in Jimma town: Is HIV/AIDS influencing the pattern of child mortality,.

[23] D. Amare, G. Belaineh, and T. Fasil, "Determinants of underfive mortality in Gilgel Gibe Field Research Center, Southwest Ethiopia," Ethiopian Journal of Health Development, vol. 21, no. 2, pp. 117-124, 2007.

[24] S. Seyoum and E. Wencheko, "Determinants of mortality among one to four years old children in Ethiopia: a study based on the 2011 EDHS data," Ethiopian Journal of Health Development, vol. 27, no. 1, pp. 8-15, 2013.

[25] Y. Mekonnen, B. Tensou, D. S. Telake, T. Degefie, and A. Bekele, "Neonatal mortality in Ethiopia: trends and determinants," BMC Public Health, vol. 13, no. 1, article 483, 2013.

[26] W. Negera, "Risk factors of neonatal mortality in Ethiopia," Ethiopian Journal of Health Development, vol. 27, no. 3, 2013.

[27] A. F. Dadi, "A systematic review and meta-analysis of the effect of short birth interval on infant mortality in Ethiopia," PLoS ONE, vol. 10, no. 5, Article ID e0126759, 2015.

[28] S. A. Sathiya, "Child mortality rate in Ethiopia," Iranian Journal of Public Health, vol. 41, no. 3, pp. 9-19, 2012.

[29] M. Desta, "Infant and Child Mortality in Ethiopia, The role of Socioeconomic, Demographic and Biological factors in the previous five years period of 2000 and 2005”.

[30] J. E. Lawn, S. Cousens, and J. Zupan, "4 Million neonatal deaths: when? Where? Why?” The Lancet, vol. 365, no. 9462, pp. 891900, 2005.

[31] B. Girma and Y. Berhane, "Children who were vaccinated, breast fed and from low parity mothers live longer: a community based case-control study in Jimma, Ethiopia," BMC Public Health, vol. 11, article 197, 2011. 
[32] G. A. Biks, Y. Berhane, A. Worku, and Y. K. Gete, "Exclusive breast feeding is the strongest predictor of infant survival in Northwest Ethiopia: a longitudinal study," Journal of Health, Population and Nutrition, vol. 34, no. 1, 2015.

[33] M. Fantahun, "Patterns of childhood mortality in three districts of north gondar administrative zone. A community based study using the verbal autopsy method," Ethiopian Medical Journal, vol. 36, no. 2, pp. 71-81, 1998.

[34] A. Deribew, G. A. Tessema, K. Deribe et al., "Trends, causes, and risk factors of mortality among children under 5 in ethiopia, 1990-2013: findings from the global burden of disease study 2013," Population Health Metrics, vol. 14, no. 1, article no. 42, 2016.

[35] M. Asnake, C. Larson, and G. E. Teka, "Water handling practices and their association with childhood diarrhea," Ethiopian Journal of Health Development, vol. 6, pp. 9-16, 1992.

[36] M. Fantahun, Y. Berhane, S. Wall, P. Byass, and U. Högberg, "Women's involvement in household decision-making and strengthening social capital-crucial factors for child survival in Ethiopia," Acta Paediatrica, International Journal of Paediatrics, vol. 96, no. 4, pp. 582-589, 2007.

[37] G. T. Bicego and J. T. Boerma, "Maternal education and child survival: A comparative study of survey data from 17 countries," Social Science and Medicine, vol. 36, no. 9, pp. 1207-1227, 1993.

[38] M. Gizaw, M. Molla, and W. Mekonnen, "Trends and risk factors for neonatal mortality in Butajira District, South Central Ethiopia, (1987-2008): a prospective cohort study," BMC Pregnancy and Childbirth, vol. 14, article 64, 2014.

[39] M. Asefa, R. Drewett, and F. Tessema, "A birth cohort study in South-West Ethiopia to identify factors associated with infant mortality that are amenable for intervention," Ethiopian Journal of Health Development, vol. 14, no. 2, 2000.

[40] M. Koblinsky, F. Tain, A. Gaym, A. Karim, M. Carnell, and S. Tesfaye, "Responding to the maternal health care challenge: The Ethiopian Health Extension Program," Ethiopian Journal of Health Development, vol. 24, no. 1, pp. 105-109, 2010.

[41] H. Banteyerga, "Ethiopia’s Health Extension Program: Improving health through community involvement," MEDICC Review, vol. 13, no. 3, pp. 46-49, 2011.

[42] B. Debebe and D. Tariku, "Trends and determinants of underfive mortality in amhara region, ethiopia using EDHS (2000 2011)," Journal of Health, Medicine and Nursing, vol. 28, 2016. 


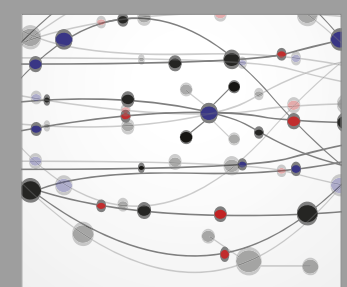

The Scientific World Journal
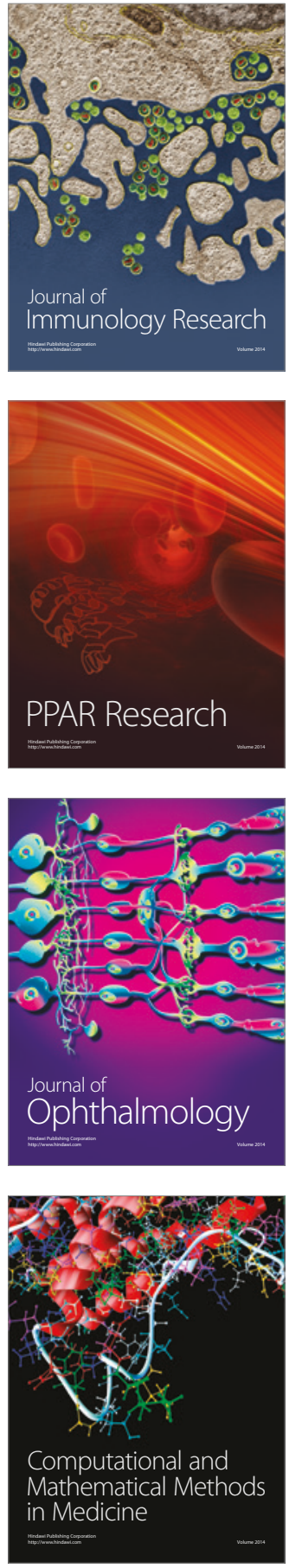

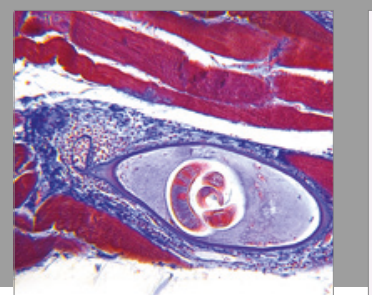

Gastroenterology Research and Practice
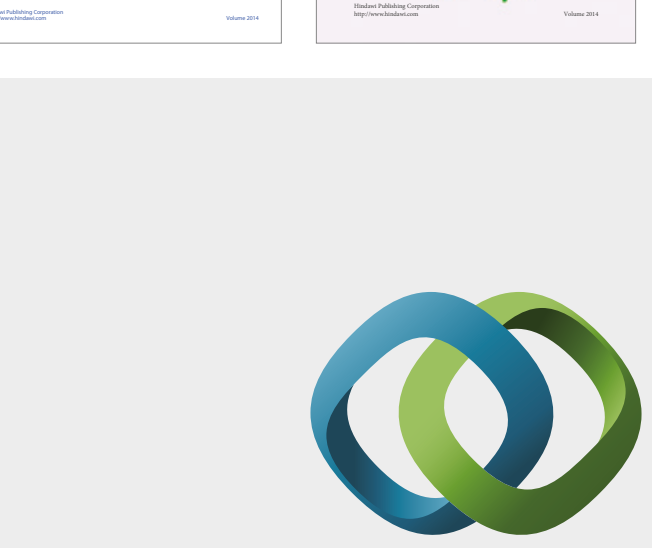

\section{Hindawi}

Submit your manuscripts at

https://www.hindawi.com
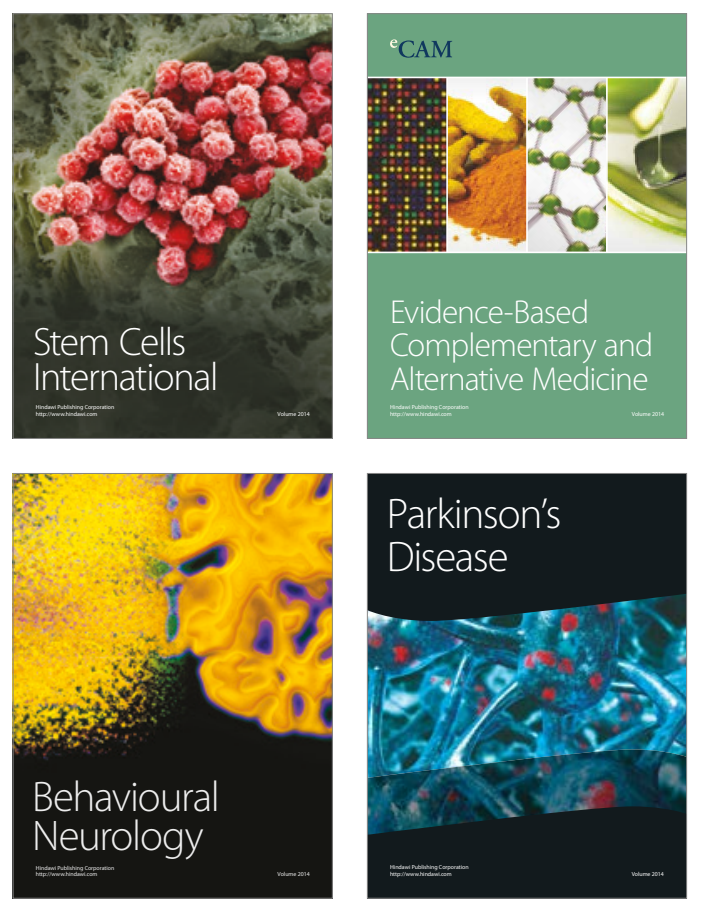
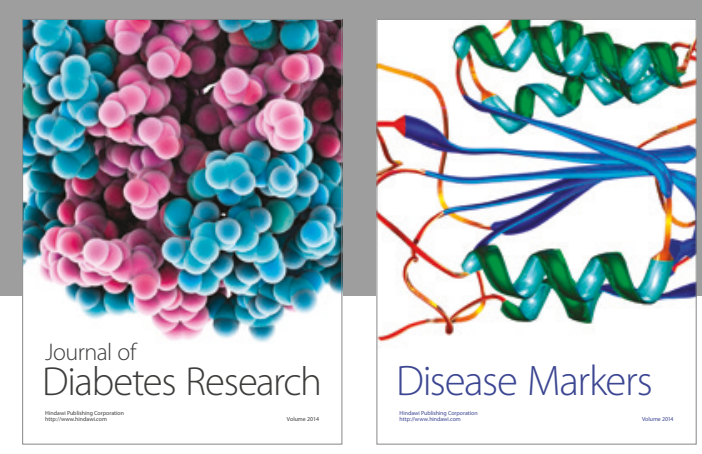

Disease Markers
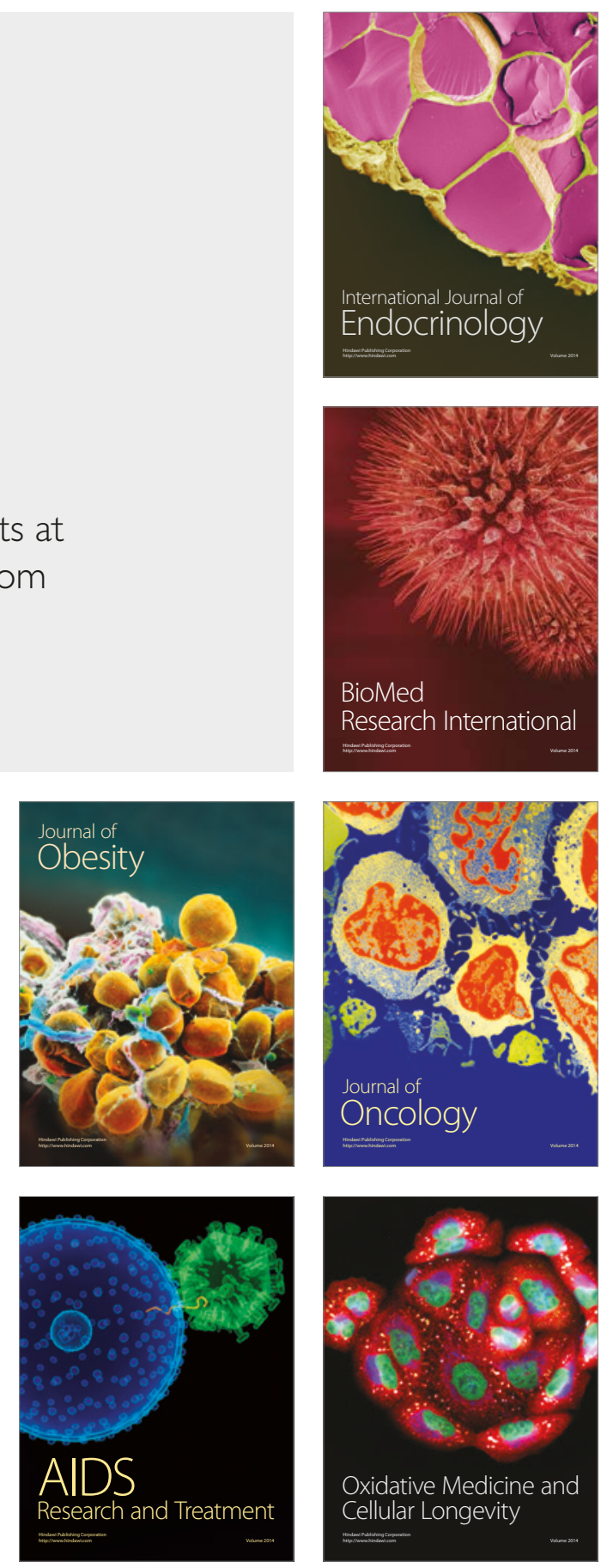